REVIEW

\title{
Muscle activity during the golf swing
}

\author{
A McHardy, H Pollard
}

Br J Sports Med 2005;39:799-804. doi: 10.1136/bjsm.2005.020271

In the right hands, the golf swing is a motion that inspires looks of awe from the public. It is a complex movement of the whole body to generate power to a golf ball to propel the ball great distances with accuracy. This movement relies on the coordinated sequence of muscle activation to produce a fluid and reproducible movement. This paper reviews the literature on golf swing related muscle activity. The phases of this activity are discussed with a view to assisting the practitioner in understanding the swing. Such understanding may help in the management of the injured golfer.

See end of article for authors' affiliations

....................

Correspondence to: Mr McHardy, Macquarie Injury Management Group, Macquarie University, Sydney 2109, NSW, Australia; ajmchardy@optushome. com.au

Accepted 6 June 2005

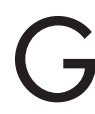
olf is a popular recreational past time in Australia and throughout the world. ${ }^{1}$ The golf swing is a complex movement involving the whole body and is used to develop momentum that is transferred to the golf ball to propel it towards the target. This movement pattern requires a coordinated sequence of muscle activity to efficiently transfer the power generated by the swing. The purpose of this research is to review the muscle activity that occurs during the golf swing. This paper presents a review of the synergistic action of the muscles of the upper and lower body during the golf swing and discusses how these muscles are recruited during the different swing phases. For the purpose of this paper, all swing related activity refers to a right handed golf swing unless otherwise noted. By understanding the component parts of the golf swing, the clinician may be able to better construct a sports specific management programme. Such a management programme could target specific muscles and actions to improve function and reduce injury producing mechanics.

\section{METHODOLOGY}

A Medline search was conducted on studies carried out between 1965 and the present. The key words golf, swing, and electromyographic were used. A hand search of references in selected papers and Science and golf: proceedings of the World Scientific Congress of Golf books were also reviewed. Research papers that fit the criterion of being an electromyographic (EMG) analysis of the golf swing were reviewed, and the data collated were used to provide an overview of the muscle activity that occurs throughout the body during the golf swing.

\section{RESULTS}

There were 12 studies that fitted the Medline search criteria, with an additional three studies found in Science and golf: proceedings of the World Scientific Congress of Golf (table 1).

Most of the literature has focused on the EMG analysis of the shoulder and lower back. ${ }^{2-13}$ Very little research has been conducted on the forearm and lower limb during the golf swing, ${ }^{414} 15$ and one study compared expert and novice differences in muscle activity during the golf swing. ${ }^{16}$ However, the latter paper merely reported that there was larger variation in muscle activity in the novice golfers than the expert golfers, with no data on muscle activity reported. The injury literature has determined that the lower back, wrist, and elbow are the three most common sites of golf related injury. ${ }^{17}{ }^{18}$ Although there is EMG analysis of back muscle activity, only one paper ${ }^{14}$ has investigated muscle activity of common forearm and wrist injury sites.

A number of papers have investigated the function of the shoulder muscles during the golf swing. ${ }^{7-9}$ Research at the Kerlan Jobe Orthopaedic Clinic, Los Angeles, California collected data from different golfer groups. ${ }^{7-9}$ Male professional golfers were the subjects in one study. The data were then reported again on sequential occasions after the addition of subjects/groups (women, amateurs) to the data set and after advances in technology. The final paper by Pink et al reports on the combined data, which are used in this review. Studies performed by Kao et $a l^{5}$ and Jobe et $a l^{10}$ analysed scapular and rotator cuff function during the golf swing. The activity of the trunk activity, both anterior and posterior, ${ }^{2}{ }^{3}$ the lower limbs, ${ }^{4}$ and the forearm ${ }^{14}$ during the golf swing have been the focus of other separate studies.

In total, 17 muscle groups were investigated in the nine papers analysed. A number of the muscles were divided into upper and lower or anterior, middle, and posterior sections. Table 2 summarises the muscles selected for EMG analysis.

Many of the trunk/axial muscle groups and the proximal appendicular muscles have been evaluated during the golf swing and are reported in table 2 .

The studies generally break down the golf swing into the following five phases (fig 1 ):

- Back swing: ball address to top of back swing

- Forward swing: top of swing to club horizontal (early part of down swing)

- Acceleration: horizontal club to impact (late part of down swing)

Abbreviations: EMG, electromyographic; MMT, manual muscle strength testing 


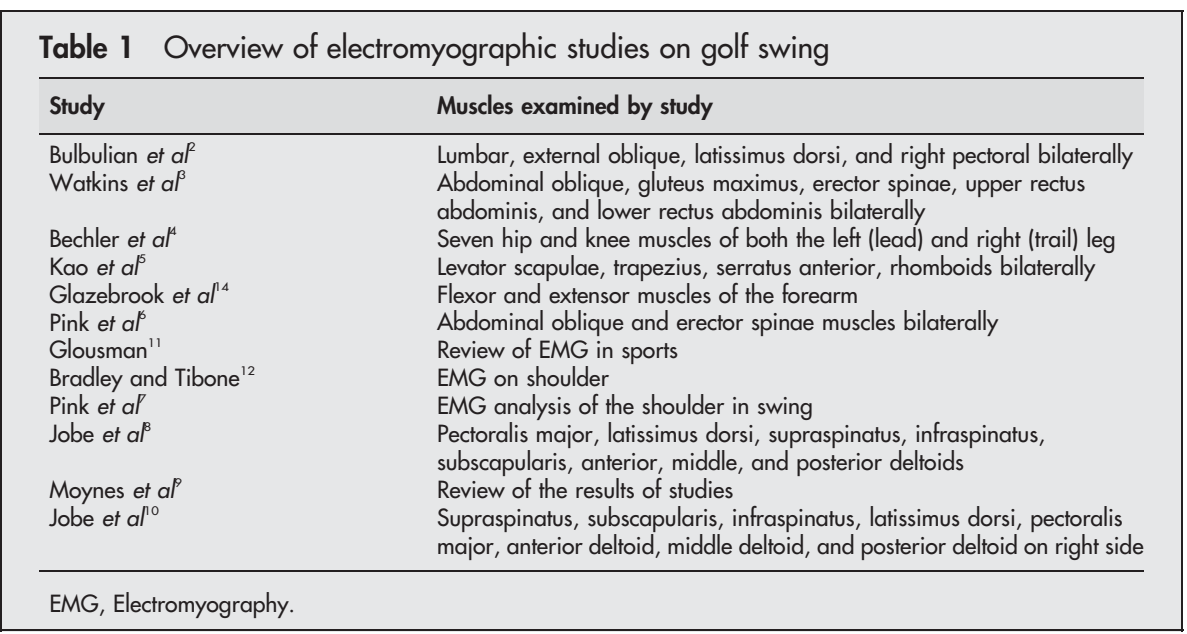

- Early follow through: impact to horizontal club

- Late follow through: horizontal to completion of swing

Either the Basmajian single needle technique ${ }^{19}$ or surface electrodes were used to collect muscle activity data. Before conduction of the golf swings, a peak one second EMG signal during manual muscle strength testing (MMT) was selected as a normalising value ( $100 \%)$ for each muscle tested. Tables 3 and 4 summarise the results of most active muscles in the upper and lower body respectively.

\section{Back swing (in the right handed golfer)}

The back swing starts from the time the club starts movement to the top of the back swing. During the back swing, the most active muscle in the upper body is the upper trapezius on the right side (52\% MMT), with the middle trapezius displaying the second highest reading (37\% MMT). On the left side, the highest reading occurred in the subscapularis (33\% MMT) followed by the upper serratus (30\% MMT). In contrast, the most active muscle in the lower body is the semimembranosus and the long head of the biceps femoris on the right side (28\% MMT and 27\% MMT). On the left side, the most active muscle is the erector spinae (26\% MMT) and the abdominal oblique (24\% MMT).

\section{Forward swing}

The forward swing starts at the top of swing and ends when the club is horizontal to the ground (early part of down swing). The most active muscle in the upper body during this phase in the upper body on the left side is the rhomboid $(68 \%$ MMT) and middle trapezuis (51\% MMT). On the right side, the most active muscles are the pectoralis major (64\% MMT) and upper serratus (58\% MMT). The most active muscle during the forward swing phase in the lower body are the upper and lower gluteus maximus (100\% MMT and 98\% $\mathrm{MM})$ on the right side along with the biceps femoris $(78 \%$ MMT). On the left side, the most active muscles are the vastus lateralis (88\% MMT) and the adductor magnus (63\% MMT).

\section{Acceleration}

The acceleration phase starts from the horizontal club to the impact of the ball (late part of down swing). This phase of the swing sees the pectoralis major muscle bilaterally being the most active muscle (93\% MMT bilaterally) in the upper body. On the right side, the second most active muscle is the upper serratus anterior (69\% MMT). On the left side, the levator scapulae is the second most active muscle (62\% MMT).

In the lower body, the acceleration phase sees the left biceps femoris (83\% MMT) being the most active muscle with the left upper and lower gluteus maximus, along with the vastus lateralis being the second most active muscles (58\% MMT). On the right side, the abdominal oblique (59\% MMT) is the most active muscle, followed by the gluteus medius (51\% MMT).

\section{Early follow through}

The early follow through starts at impact to when the club is horizontal to the ground. In the upper body, the most active muscle during the early follow through is the pectoralis major bilaterally (74\% MMT), followed by the right subscapularis (64\% MMT) and the infraspinatus on the left (61\% MMT). The most active muscle in the lower body during the early follow through is the left long head of biceps femoris $(79 \%$ MMT), and left vastus lateralis (59\% MMT). The right gluteus medius (59\% MMT) is the most active right sided muscle, followed by the abdominal oblique (51\% MMT).

Table 2 Muscles studied in the golf swing by electromyographic analysis

\begin{tabular}{lll}
\hline Upper body & Trunk & Lower body \\
\hline Trapezius & Rhomboids & Adductor magnus \\
Upper & Serratus anterior & Long head biceps femoris \\
Middle & Upper & Semimembranosus \\
Lower & Lower & Vastus lateralis \\
Levator scapulae & Latissimus dorsi & \\
Supraspinatus & Abdominal obliques & \\
Subscapularis & Rectus abdominus & \\
Deltoid & Upper & \\
Anterior & Lower & \\
Middle & Erector spinae & \\
Posterior & & \\
\hline
\end{tabular}



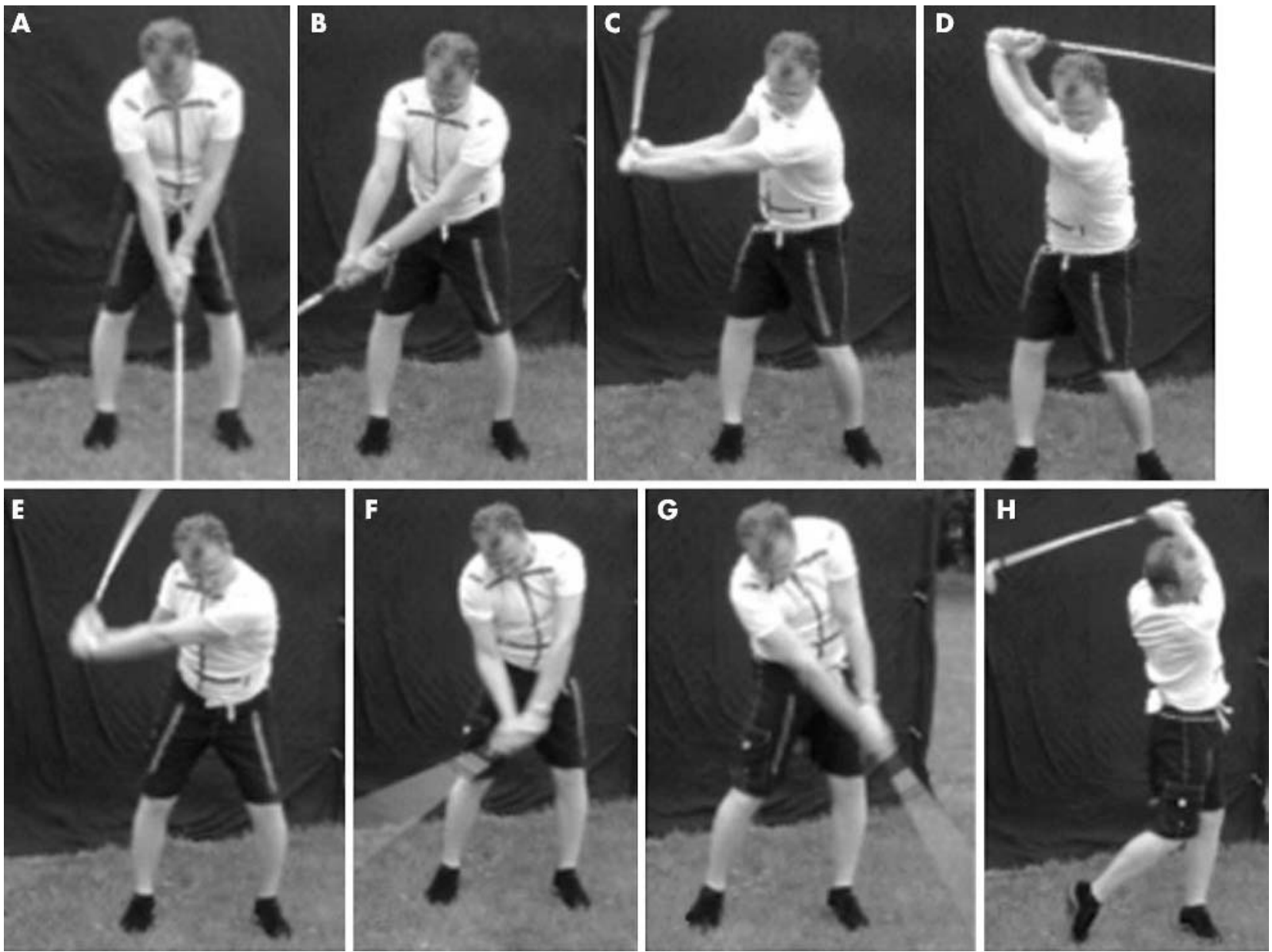

Figure 1 Phases of the golf swing. (A) Address position; (B) early back swing; (C) late back swing; (D) top of swing; (E) down swing; (F) acceleration; (G) early follow through; $(\mathrm{H})$ late follow through. The subject has given permission for publication of this figure.

\section{Late follow through}

The late follow through starts when the club is horizontal to the ground and ends at the completion of the swing. The most active muscles in the upper body during the late follow through on the left are the infraspinatus (40\% MMT) and the pectoralis major (39\% MMT). On the right side, the most active muscles are the subscapularis (56\% MMT), followed by the upper and lower serratus anterior (40\% MMT).

In the lower body, the most active left sided muscles are the semimembranosus and vastus lateralis (42\% MMT each), followed by the adductor magnus (35\% MMT). On the right, the vastus lateralis muscle $(40 \% \mathrm{MMT})$ is the most active muscle followed by the gluteus medius (22\% MMT).

\section{DISCUSSION}

The classic golf swing, predominantly used in the early part of the twentieth century, involved a relatively equal amount of lumbopelvic and shoulder rotation during the back swing. The follow through position was characterised by a relatively neutral spinal position and the momentum of the player moving forward. ${ }^{18}$

The modern golf swing was made popular by Jack Nicklaus and is currently used by most current professional players. It involves a limited lumbopelvic rotation in the back swing resulting in a greater relative rotation of the torso compared with the classic swing. The follow through is characterised by a hyperextended spinal position, known as the reverse " $\mathrm{C}$ ".

\begin{tabular}{|lll|}
\hline \multicolumn{3}{|c|}{$\begin{array}{l}\text { Table } 3 \\
\text { of Summary of most active muscles in upper body/trunk during the different phases } \\
\text { of the golf swing (percentage of maximal manual testing) }\end{array}$} \\
\hline Phase of swing & Left upper body/trunk & Right upper body/trunk \\
\hline Back swing & Subscapularis (33\%) & Upper trapezius (52\%) \\
& Upper serratus (30\%) & Middle trapezuis (37\%) \\
Forward swing & Rhomboid (68\%) & Pectoralis major (64\%) \\
& Middle trapezius (51\%) & Upper serratus (58\%) \\
Acceleration & Pectoralis major (93\%) & Pectoralis major (93\%) \\
Early follow through & Levator scapula (62\%) & Upper serratus (69\%) \\
& Pectoralis major (74\%) & Pectoralis major (74\%) \\
Late follow through & Infraspinatus (61\%) & Subscapularis (64\%) \\
& Infraspinatus (40\%) & Subscapularis (56\%) \\
& pectoralis major (39\%) & Upper and lower serratus (40\%) \\
\hline
\end{tabular}




\begin{tabular}{|c|c|c|}
\hline Phase of swing & Left lower body/trunk & Right lower body/trunk \\
\hline Back swing & $\begin{array}{l}\text { Erector spinae ( } 26 \%) \\
\text { Abdominal oblique (24\%) }\end{array}$ & $\begin{array}{l}\text { Semimembranosus ( } 28 \%) \\
\text { Long head of the biceps femoris }(27 \%)\end{array}$ \\
\hline Forward swing & $\begin{array}{l}\text { Vastus lateralis (88\%) } \\
\text { Adductor magnus (63\%) }\end{array}$ & $\begin{array}{l}\text { Upper and lower gluteus maximus } \\
\text { (100\% and } 98 \%) \\
\text { Biceps femoris }(78 \%)\end{array}$ \\
\hline Acceleration & $\begin{array}{l}\text { Biceps femoris ( } 83 \% \text { ) } \\
\text { Upper and lower gluteus maximus, } \\
\text { vastus lateralis (58\%) }\end{array}$ & $\begin{array}{l}\text { Abdominal oblique (59\%) } \\
\text { Gluteus medius (51\%) }\end{array}$ \\
\hline Early follow through & $\begin{array}{l}\text { Long head of biceps femoris (79\%) } \\
\text { Vastus lateralis (59\%) }\end{array}$ & $\begin{array}{l}\text { Gluteus medius (59\%) } \\
\text { Abdominal oblique (51\%) }\end{array}$ \\
\hline \multirow[t]{2}{*}{ Late follow through } & $\begin{array}{l}\text { Semimembranosus and vastus } \\
\text { lateralis }(42 \%)\end{array}$ & Vastus lateralis $(40 \%)$ \\
\hline & Adductor magnus (35\%) & Gluteus medius (22\%) \\
\hline
\end{tabular}

The momentum is directed upwards. This swing is thought to deliver more power to the shot and a higher ball trajectory. It is the most popular golf swing, both in the professional and amateur ranks. ${ }^{18}$

The clinician often sees patients presenting with a golf related injury. Many of these injuries occur as the result of golf swing mechanics and are soft tissue injuries. An understanding of golf swing mechanics is important in determining the aetiology and management of golf related injury. The back swing is characterised by a rotation of the shoulder girdle to the right, with right arm abduction flexion and external rotation and corresponding left arm adduction, flexion and internal rotation to take back the golf club. The right scapula retracts and the left scapula protracts as they move around the trunk in a clockwise movement. Thus the muscles most active in the back swing are located in the upper body. The upper and middle trapezius are the most active muscles on the right. On the left side, the subscapularis and serratus anterior muscles facilitate internal rotation of the arm and protract the scapula.

The lumbopelvic region has limited rotation to the right in the modern swing, with the pelvic muscles providing a stable base for the trunk to rotate. The lumbopelvic movement results from hamstring group activation as the body weight transfers to the right side. The left oblique also contracts to aid this trunk rotation in the back swing.

The down swing is often reported as being made up of two arbitrary components, the forward swing (the early down swing) and the acceleration phase, which begins when the club is parallel to the ground. The early phase of the down swing is characterised by the return of the body back to the ball in preparation to hit it. In the modern golf swing, the hip initiates this movement and rotates the pelvis to the left. The right gluteals are very active in the extension of the right hip. The right biceps femoris contracts strongly to aid in the transfer of body weight back to the left side. The left pelvic muscles are active to provide a pivot point for the left lumbopelvic rotation, and weight transfer is enhanced by the activity of the vastus lateralis and adductor magnus.

In the upper body, the arms rapidly return the down swing in preparation to hit the ball. This combined movement of left rotation of the shoulder girdle and scapular rotation in an anti-clockwise direction around the trunk results in large activity of the left medial scapulae stabilisers/retractors. Muscle activity on the right side is high in the pectoralis major in the initiation of internal shoulder rotation and flexion, and the upper serratus anterior contracts to assist scapular protraction.

The acceleration phase of the golf swing continues the down swing to the ball impact. This phase of the swing is the most active phase of the entire golf swing. The major movers of the shoulder girdle, the pectoralis, are the most active muscles. The right side continues the activity achieved during the early down swing, while the left pectoralis appears to maintain an eccentric contraction to control the left arm abduction and external rotation. On the right side, the upper serratus is still active to protract the scapula. On the left side, the levator scapulae are also active to help with the scapular tilting. In the forearms, there is what is termed the "flexor burst" during this phase. ${ }^{14}$ This refers to a large increase in wrist flexor muscle activation just before the point of impact.

The acceleration phase also sees activity of the lower body, which is characterised by the left lateral leg and lumbopelvic stabilisers being strongly activated. The muscles are active to provide a solid base for subsequent rotation of the trunk in the process of hitting the ball. On the right side, the obliques are the most active muscles and assist the rotation of the trunk back to the ball from the right rotated (back swing) position. At the level of the hip, the gluteus medius is also active to aid in this rotation.

\section{Muscle function at point of impact}

Although the impact of the golf swing is a specific point in time, and instantaneous muscle activity is difficult to evaluate, it is important to know what is occurring in the body at this time. This is important because most golf injuries occur at impact. Just before impact there is an increase in right wrist flexor activation, the flexor burst, which corresponds to combined flexion and pronation of the right forearm that occurs through impact. If there is a sudden decrease in clubhead acceleration-for example hitting the ground or tree root etc-there is a sudden change from concentric to eccentric contraction in the wrist flexors. This stretch based injury is likely to be acute if forces are large enough, or overuse-type if it occurs regularly.

The early follow through of the golf swing occurs after ball impact and is the phase at which deceleration of the trunk rotation occurs. The pectoralis major muscles continue to be very active, continuing their action of the acceleration phase. The other muscles that are active in the follow through are the right trunk external rotators and the left side internal rotators. This rotational activity is associated with similar paired activity in the shoulder. In the shoulder, the active muscles are the right subscapularis and the left infraspinatus. These muscles are active during impact, where there is a "rolling" of the forearms, which results in left arm supination and right arm pronation. This movement continues through early follow through resulting in left arm external rotation and right arm internal rotation. The rotator cuff muscles contract to control this movement.

It is noteworthy that a lack of trunk rotation may require the much smaller shoulder rotators to become excessively 


\section{What is already known on this topic}

- A number of studies have analysed the muscles of the shoulder girdle and trunk during the golf swing using EMG

- Many of the subjects were professionals or players with low handicaps - that is, highly skilled golfers

active to maintain the swing momentum or decelerate it. Such a scenario may result in the shoulder dysfunction often noted in golfers, particularly instability in professionals. It is also noteworthy that those with back problems may potentially induce a shoulder problem in their attempt to reduce the loads on a painful lower back. Bulbulian et $a l^{2}$ noted similar observations in his research on a modified golf swing where the back swing is shortened. This research reported that the forces generated in the lower back were reduced by this swing, but the forces generated in the shoulder were greater.

The lower body muscle activity is similar to the acceleration phase, with the left side acting as a stable base and the right side rotating around the left.

In the late follow through, the muscle activity decreases as the golfer nears the end of the swing. The muscle activity in this phase is similar to the early follow through, but with a lesser degree of activity. The only exception occurs in the upper body where the right serratus anterior shows increased activity, as it aids the protraction of the scapular around the trunk.

During the follow through of the golf swing, a number of muscles are eccentrically loaded to aid the deceleration of the body and golf club. This is particularly true of the rotator cuff musculature. Eccentric muscle has the potential for injury because of the forces produced on muscle fibres. ${ }^{20-22}$ This review proposes that such a mechanism is inherent in the genesis of golf related shoulder injury.

There are a number of methodological concerns about many of the studies on the EMG activity of the golf swing. All of the golfers selected in the studies were right handed. This aids standardisation of the data, and the results can be extrapolated to most golfers as most are right handed. However, left and right handed golfers may be different, and it is an assumption that EMG activity in the left handed golfer is a mirror image of the right handed golfer.

Secondly, most studies were conducted on highly skilled golfers (professional or low handicap, $<5$, amateurs). In the United States, the average handicap is 16.1 for male golfers ${ }^{23}$ and 29.2 for female golfers, ${ }^{24}$ and in Australia, they are 18.1 and 27.5 respectively. ${ }^{25}$ Although the data collected may represent what ideally should occur during the golf swing, it may not accurately reflect the actual swings of most golfers. The "average" golfer is a very different quality of player, who would be expected to have a less reproducible and efficient golf swing, with potentially different muscle activity during the swing from a highly skilled golfer. Extrapolation of the data from one cohort to the other may therefore be problematic.

Finally, the methods sections of the included studies do not have a description of the golf swing used by the subjects. As described previously, there are a number of different swing types in golf. Each swing has a distinct characteristic body motion, which may produce different muscle activation throughout the golf swing and alter the data collected. In addition, a third swing has begun to emerge. Components of both the classic and modern swing have been incorporated to produce what may be termed the "hybrid swing". The hybrid
What this study adds

- All EMG studies relevant to the golf swing were synthesised, enabling explanation of why certain muscles are active during specific phases of the swing in relation to the movement of the body during the swing

- The methodology of the EMG studies was evaluated and it was concluded that further studies are required on golfers of different skill levels and with different swing types to determine if there are differences in these subgroups

swing uses a similar back swing to the modern swing, with limited lumbopelvic rotation, whereas the follow through is similar to the classic swing, with a relatively neutral spine position (less hyperextension). The momentum of the follow through is directed into left rotation in the right handed golfer. $^{18}$

It is important that further studies of the EMG activity of the golf swing target the aforementioned methodological issues. Future studies could investigate both the upper and lower body activity in beginner/low level golfers (handicap $>25$ ), the average golfer, ${ }^{15-20}$ and the advanced golfer (professional and $<5$ handicap). These groups will allow a comparison between skill levels in golfers in terms of muscle activity and may identify potential reasons for the differences in handicaps. Studies on muscle activity that occurs during both the classic and modern swing are needed to identify if there is a difference between these swings.

Ultimately, such data could be related to prospective injury data on these swings to better explain the causes of golf related injury. These data would also help clinicians to manage golf related injury, with the prescription of appropriate exercise protocols to rehabilitate and prevent injury.

\section{Authors' affiliations}

A McHardy, H Pollard, Macquarie Injury Management Group, Macquarie University, Sydney, NSW, Australia

Competing interests: none declared

Permission has been obtained for the publication of figure 1

\section{REFERENCES}

1 Australian Bureau of Statistics. Participation in sport and physical activity. Doc No 4177. 0, 2002.

2 Bulbulian R, Ball KA, Seaman DR. The short golf backswing: effects on performance and spinal health implications. J Manipulative Physiol Ther $2001 ; 24: 569-75$.

3 Watkins RG, Uppal GS, Perry J, et al. Dynamic electromyographic analysis of trunk musculature in professional golfers. Am J Sports Med 1996;24:535-8.

4 Bechler JR, Jobe FW, Pink M, et al. Electromyographic analysis of the hip and knee during the golf swing. Clin J Sport Med 1995;5:162-6.

5 Kao JT, Pink M, Jobe FW, et al. Electromyographic analysis of the scapular muscles during a golf swing. Am J Sports Med 1995;23:19-23.

6 Pink M, Perry J, Jobe FW. Electromyographic analysis of the trunk in golfers. Am J Sports Med 1993;21:385-8.

7 Pink M, Jobe FW, Perry J. Electromyographic analysis of the shoulder during the golf swing. Am J Sports Med 1990;18:137-40.

8 Jobe FW, Perry J, Pink M. Electromyographic shoulder activity in men and women professional golfers. Am J Sports Med 1989;17:782-7.

9 Moynes DR, Perry J, Antonelli DJ, et al. Electromyography and motion analysis of the upper extremity in sports. Phys Ther 1986;66:1905-11.

10 Jobe FW, Moynes DR, Antonelli DJ. Rotator cuff function during a golf swing. Am J Sports Med 1986;14:388-92.

11 Glousman R. Electromyographic analysis and its role in the athletic shoulder. Clin Orthop Relat Res 1993;288:27-34

12 Bradley JP, Tibone JE. Electromyographic analysis of muscle action about the shoulder. Clin Sports Med 1991t; 10:789-805. 
13 Hosea TM, Gatt CJ, Galli NA et al. Biomechanical analysis of the golfer's back. In: Cochran A, eds. Science and golf: proceedings of the World Scientific Congress of Golf. London: E \& FN Spon, 1990:43-8.

14 Glazebrook MA, Curwin S, Islam MN, et al. Medial epicondylitis. An electromyographic analysis and an investigation of intervention strategies. Am J Sports Med 1994;22:674-9.

15 Barclay JK, Mcllroy WE. Effect of skill level on muscle activity in neck and forearm muscles during the golf swing. In: Cochran A, eds. Science and golf: proceedings of the World Scientific Congress of Golf. London: E \& FN Spon, 1990:49-53.

16 Abernethy B, Neal RJ, Parker AW, et al. Expert-novice differences in muscle activity during the golf swing. In: Cochran $A$, eds. Science and golf: proceedings of the World Scientific Congress of Golf. London: E \& FN Spon, 1990:54-60.

17 Theriault G, Lachance P. Golf injuries. An overview. Sports Med 1998;26:43-57.

18 McHardy AJ, Pollard HP, Luo K. Golf injuries. A review of the literature. Sports Med, 2005; in press.

19 Basmajian, JV. In: Muscles alive: their functions revealed by electromyography. Baltimore: Williams and Wilkins, 1978:23-7.

20 Lieber RL, Friden J. Mechanisms of muscle injury after eccentric contraction. J Sci Med Sport 1999;2:253-65.

21 Proske U, Morgan DL. Muscle damage from eccentric exercise: mechanism, mechanical signs, adaptation and clinical applications. J Physiol 2001;537:333-45.
22 Byrne C Twist C, Eston R. Neuromuscular function after exercise-induced muscle damage: theoretical and applied implications. Sports Med 2004;34:49-69.

23 Men's Handicap Indexes. USGA handicap department. http://www. usga.org/handicap/articles/text/mens-hcap.html (accessed 20 Dec 2004).

24 Women's Handicap Indexes. USGA handicap department. http:// www.usga.org/handicap/articles/text/womens-hcap.html (accessed 20 Dec 2004)

25 Australian Golf Union. AGU affiliated clubs membership statistics. May, 2003.

\section{COMMENTARY}

This article brings together some good research that has gone before it, and presents it in a concise and usable way for the clinician wishing to better understand, analyse, diagnose, and manage injuries associated with the popular sport of golf.

P J Garbutt

ENHANCE Healthcare, Ngunnawal, ACT, Australia; healthcare@enhance.com.au

11 th European Forum on Quality Improvement in Health Care

26-28 April 2006, Prague, Czech Republic

For further information please go to: www.quality.bmipg.com

Book early to benefit from a discounted delegate rate 